Kebede R., Moscati A. and Johansson P. (2020). "Semantic web for information exchange between the building and manufacturing industries: a literature review" In: Proc. 37th CIB W78 Information Technology for Construction Conference (CIB W78), São Paulo, Brazil, pp. 248-265. DOI: http://dx.doi.org/10.46421/2706-6568.37.2020.paper018

\title{
SEMANTIC WEB FOR INFORMATION EXCHANGE BETWEEN THE BUILDING AND MANUFACTURING INDUSTRIES: A LITERATURE REVIEW
}

\author{
Rehel Kebede $^{1}$, Annika Moscati ${ }^{2}$, and Peter Johansson ${ }^{3}$
}

\begin{abstract}
Easy and solid information exchange constitutes an important part in BIM-based projects. To conduct reliable simulations and optimizations, information about products, such as luminaries, windows, doors, etc., need to be provided by the manufacturing industries to the building designers at the early design stage. Several studies and ongoing researches presented the Semantic Web (SW) and Linked Data (LD) technologies as an interoperable and flexible approach for providing product information from the manufacturers during the design and construction stage as well as gathering consumers data to the manufacturers during the operation stage. A systematic literature review has been conducted to investigate benefits and limitations of using the SW and LD technologies for developing product data templates for information exchanges between the building and product manufacturing industries in comparison with the conventional approach of information ex-changes using the openBIM standards. Results show that SW and LD could apport considerable benefits to the information exchange in the building sector. Moreover, SW and LD technologies enable the sharing of products' information from manufacturers to designers who can search product information, compare different products and take informed design decisions during the very beginning of the design process.
\end{abstract}

Keywords: Product Data Template, Semantic Web, Information Exchange.

\section{INTRODUCTION}

The increasing digitalization in the construction and facility management industry has led to a growing use of virtual computer models and is the prerequisite for data, sensor and simulation driven product development where features of the complex products can be simulated and evaluated. However, this development creates challenges and opportunities for industries delivering products used in construction. The construction industry is the largest single sector in most countries and an important trading partner for the manufacturing industry. Its highly complex products are to a large degree an aggregation of products realized by the manufacturing industry. The growing use of virtual computer models in the different stages of the products' life cycle will put new demands on the information linked to products delivered by the manufacturing industry. In the design stage for example, techniques like parametric design, optimization and multi-criteria decision-making allow the evaluation of thousands of alternative solutions for a built environment (Jalilzadehazhari et al., 2019b, Jalilzadehazhari et al., 2019a). One of the out-comes from this development is that a huge number of products could be

Doctoral Student, https://ju.se/, Jönköping, Sweden, kebreh@ju.se

Senior Lecturer, https://ju.se/, Jönköping, Sweden, annika.moscati@ju.se

Associate Professor, https://ju.se/, Jönköping, Sweden, peter.johansson@ju.se 
evaluated in the design phase and from such, the final choice of product could be done. For this to be practically usable though, the information about products need to be automatically retrieved (Jalilzadehazhari et al., 2017, Negendahl, 2015).

In this context, the issue concerns not only the information content, but primarily its storage, querying and reasoning. The research developments in this area focus on the possibility to retrieve information using databases or web links instead of traditional file exchange or centralized file model repositories (Pauwels et al., 2017), the need for flexible systems that enable an easier information updated (Cavka et al., 2017, Zhang et al., 2015) and the requirements for new standards (Zhang et al., 2015, Eastman et al., 2011).

Several initiatives to define and structure product properties are active at present, e.g. the work in CEN/TC 169/WG 1 concerning BIM Properties for Lighting Luminaires and Sensors. In some of these efforts it has been stated that the base for defining product properties should be the different standards (CEN, ASTM, AU, ISO etc) used to evaluate these properties. It has also been shown that there is a big gap be-tween how products are described by designers in the building industry as well as designers in the manufacturing industry. To overcome this gap, efforts are made to standardize (Product) Data Templates (DT) for different categories of products. Most of these works are based on the so called "PPBIM" (prEN ISO 23386/23387) which describes a methodology and the framework for properties and Data Templates. One of the main tools in the methodology are dictionaries. The dictionaries should contain the definitions of the attributes describing a property of a product and give each attribute a GUID. The buildingSMART Data Dictionary (bsDD) is one example of such a Dictionary, and probably the most referred one. It has also been stated that bsDD should contain and uniquely define the DTs, by giving each DT a GUID.

Despite standardization efforts, there is no globally agreed product data standard available by which product data can be created and provided by the manufacturers digitally (UKBIM, 2018).

Completed and ongoing studies suggest Semantic Web (SW) and Linked Data (LD) as technologies that allow a more interoperable and flexible approach for providing product information from the manufacturers during the design and construction stage as well as gathering consumers data to the manufacturers during the operation stage.

Therefore, a systematic literature review has been conducted in order to investigate the benefits and limitations of using the SW and LD technologies for developing product data templates for information exchanges between the building and lighting product manufacturing industries in comparison with the conventional approach of information exchanges using the openBIM standards.

The research question has been formulated using the PICOC framework further described in the "research method" section, together with the whole search strategy. From a total of 519 papers retrieved, following an analytical inclusion / exclusion criterion described in section 2.2, a total of 26 papers have been identified as relevant for the study's scope. Among them, one paper has been chosen as index paper against which concepts extracted from other retrieved papers are compared with and categorized accordingly while reporting the findings of this review.

The results will be presented as follows:

- Benefits of the Semantic Web and Linked Data Technologies, further categorized into

- ontology-based information management and sharing, 
- combine product manufacturer data with building data and

- support building performance analysis and optimization.

- Limitations of the Semantic Web and Linked Data Technologies

- Limitations of Existing BIM Technologies.

The literature review results show that many are the benefits that an extensive use of SW and LD could apport to the building sector. However, limitations will be presented and discussed, as well as suggestions for further researches. It is also important to state that this paper is part of a large research project titled Manufactured products' information provision for light environments (MAP4Light), co-funded by the Swedish Knowledge foundation (KK) together with four industrial partners. MAP4Light aims to study and develop new digital tools for product information exchange between the manufacturing and building industries focusing on products in light environments. Therefore, these two latter concepts (lighting products and environments) were included in the literature review strategy. However, the lack of papers facing these specific topics led to a more generic analysis and to the need of further studies to satisfy MAP4Light's needs.

\section{RESEARCH METHOD}

\subsection{Identifying Relevant Studies}

The systematic search process of this review follows the methodology described by Booth et al. (2016). A framework called PICOC has been used to formulate the re-search question. The acronym PICOC stands for Population and their problem, Intervention or Issue, Comparative Intervention, Outcomes or themes and Context (Booth et al., 2016). Accordingly, both the scope of the research and the different parts of the research question are identified using this framework as shown in Table 1. Formulating the research question in this manner facilitates identification of the important keywords through the process of translating the research question into its relevant search concepts.

The main source of information chosen for this study was the Scopus database because Scopus is a multi-disciplinary database with easy features to refine the search results by year, document types, authors and affiliations. It is the largest abstract and citation database of peer-reviewed papers with relatively large coverage in comparison with other databases such as Web of Science and Google Scholar (Mongeon and PaulHus, 2015, Leslie, 2013, Burnham, 2006).

As indicated in Table 1, the scope of the review is identified, and the following research question is formulated: 'What are the benefits and limitations of using the SW and LD technologies for developing product data templates for information ex-changes between the building and lighting product manufacturing industries in comparison with the conventional approach of information exchanges using the openBIM standards?'

Subsequently, the search concepts are extracted from the research question and the relevant synonyms are identified for each search concept as shown in Table 2. 
Table 1: Research question formulation using the PICOC framework

\begin{tabular}{ll}
\hline P & $\begin{array}{l}\text { Population: } \\
\text { Population and their problem }\end{array}$ \\
& $\begin{array}{l}\text { - building lighting engineers } \\
\text { Problems: } \\
\text { - Information exchange }\end{array}$ \\
\hline I & $\begin{array}{l}\text { Intervention } \\
\text { - The Semantic Web and Linked Data } \\
\text { tntervention and issue }\end{array}$ \\
& Issue: \\
& • Limitations of these technologies \\
\hline C & - The conventional approach of \\
Comparative Intervention & information exchanges using the \\
& openBIM standards \\
\hline O & - An improvement in information \\
Outcomes or themes & exchanges (improved interoperability) \\
\hline C & Building and lighting product \\
Context & manufacturing industries \\
\hline
\end{tabular}

Table 2: Search concepts and Synonyms

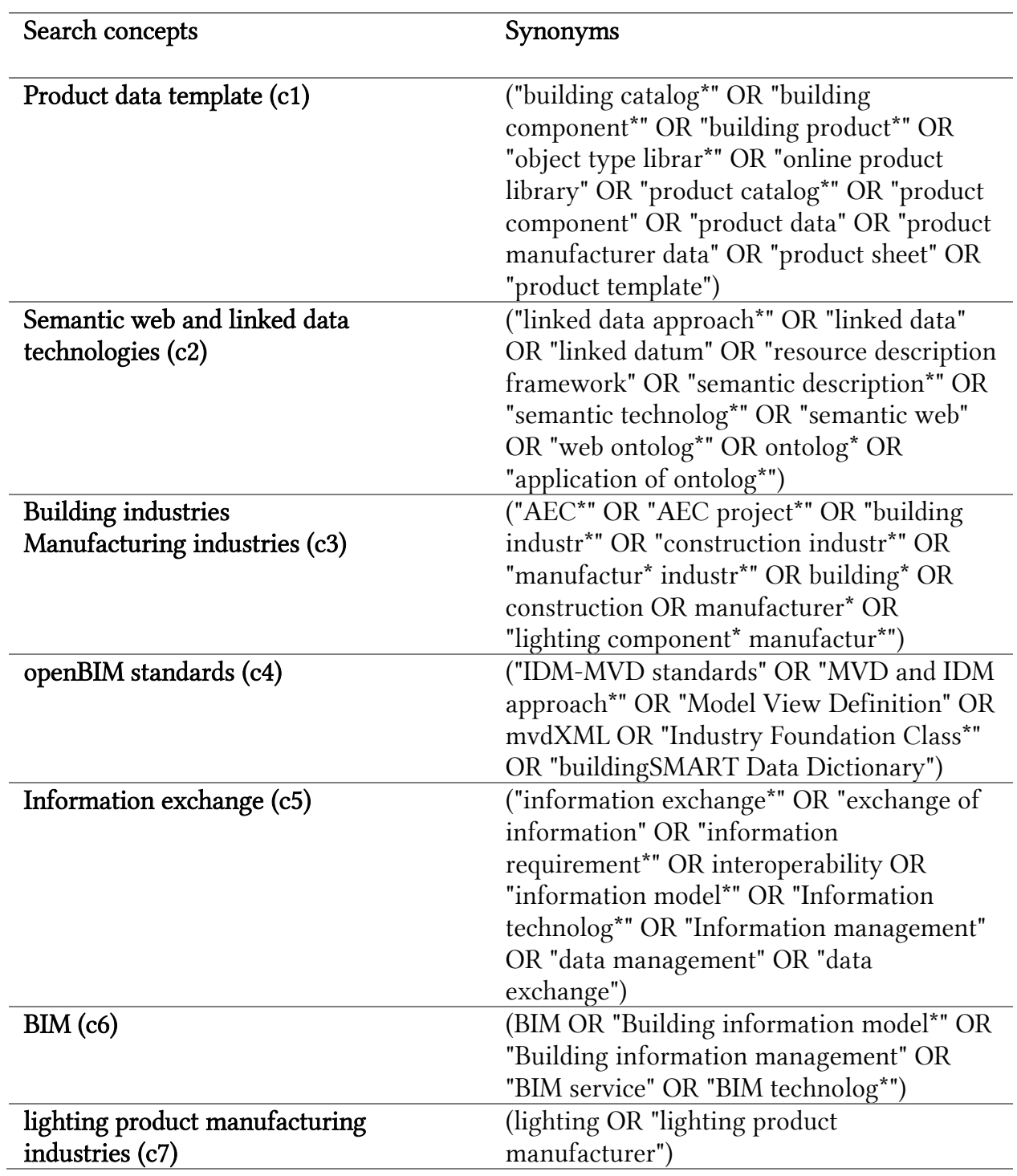


The search strategy, which is the search concepts combined with Boolean Operators, is used to locate the relevant papers. The search strategy, search result, search field and search date are given in Table 3. The most important search concepts have been used in all search combinations as a common denominator to ensure retrieval of the relevant papers.

Table 3: Search strategy, search result, search field and search date

\begin{tabular}{llll}
\hline Search strategy & $\begin{array}{l}\text { Search result /No of } \\
\text { hits }\end{array}$ & Search field & Search date \\
\hline c1 AND c2 & 348 & title-abs-key & Nov 24, 2019 \\
\hline c1 AND c2 AND c3 & 117 & title-abs-key & Nov 24, 2019 \\
\hline c1 AND c2 AND c3 & 5 & title-abs-key & Nov 24, 2019 \\
AND c4 & & title-abs-key & Nov 24, 2019 \\
\hline c1 AND c2 AND c3 & 5 & title-abs-key & Nov 24, 2019 \\
AND c4 AND c5 & & & \\
\hline c1 AND c2 AND c3 & 30 & all fields & Nov 24, 2019 \\
AND c6 & & & \\
\hline c1 AND c2 AND c5 & 13 & &
\end{tabular}

\subsection{Paper Selection Process}

A total of 519 papers were identified with the presented search strategy. Given the small number of hits, search limitation by year was not applied. All the papers were exported to 'Rayyan systematic review web application' for further paper inclusion and exclusion analysis. The following inclusion and exclusion criteria were stated during paper selection process.

Inclusion criteria:

- Papers that discuss the concepts in the research question with the aim of better information exchange using the SW and LD are to be included

Exclusion criteria:

- Papers that discuss the concepts in the research questions with a different context and aim than better information exchange will be excluded.

The paper selection process was started with removing duplicates in the first stage. The duplicates were excluded leaving 372 documents for further investigation. Second, the remaining papers were screened for inclusion by examining the titles. In total, 71 papers are left for further analysis of inclusion by reading the abstract. Finally, 25 studies were included for full-text analysis based on the stated inclusion and exclusion criteria, out of which 19 studies are included for qualitative synthesis. Additional 7 studies were added using the snowballing literature-searching technique. A total of 26 studies were included for the review and is presented in Table 4. The diagrammatic representation of the paper selection process is shown in Figure 1 with PRISMA flow diagram. 


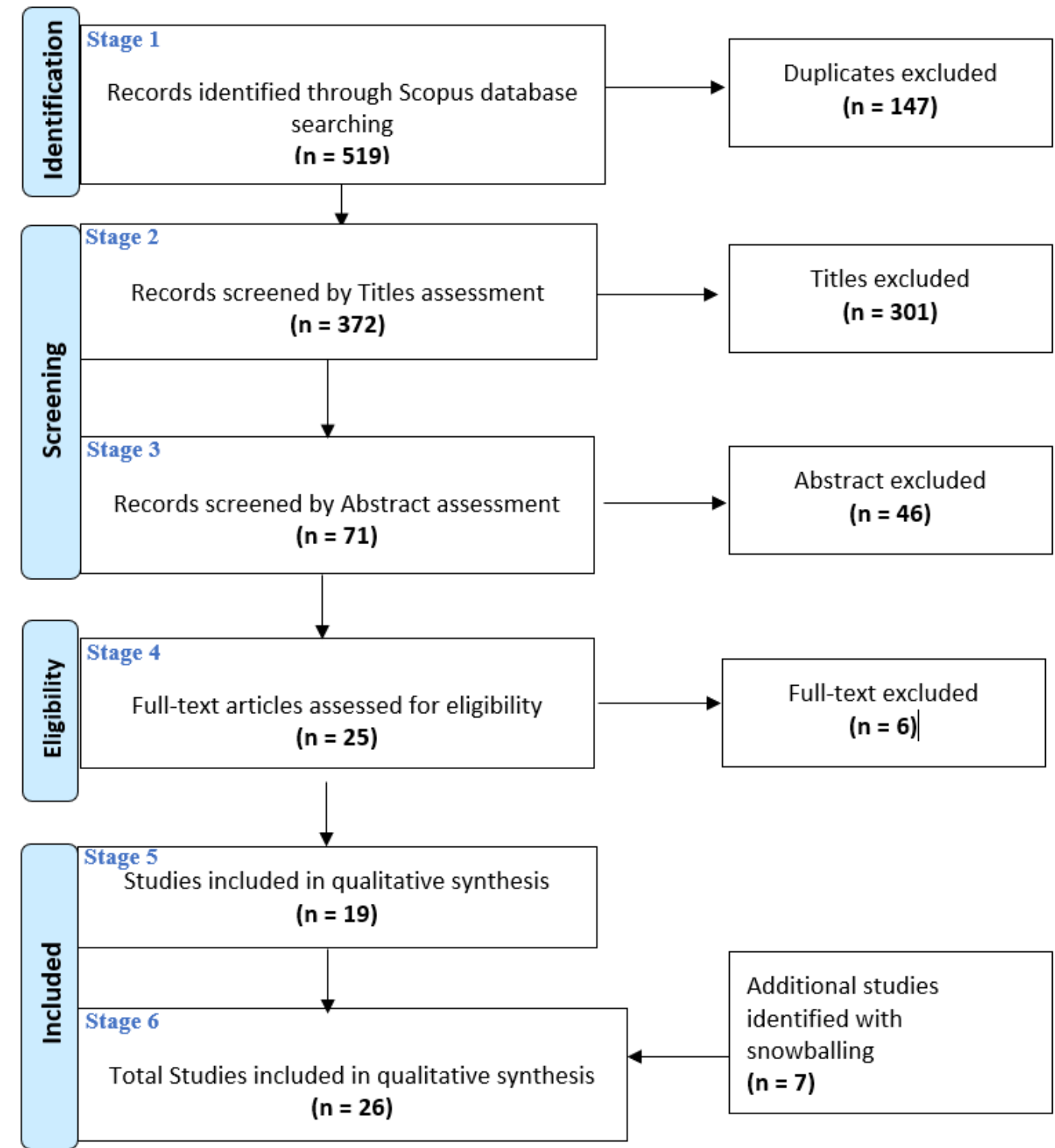

Figure 1: Paper Selection Process (PRISMA flow diagram)

Table 4 Articles Included in the Literature Review

\begin{tabular}{lll}
\hline No & Authors & Title \\
\hline 1 & Abdul-Ghafour et al. (2014) & $\begin{array}{l}\text { Semantic interoperability of } \\
\text { knowledge in feature-based CAD } \\
\text { models }\end{array}$ \\
& & $\begin{array}{l}\text { Towards the Semantic Enrichment of } \\
\text { Existing Online 3D Building } \\
\text { Geometry to Publish Linked Building } \\
\text { Data }\end{array}$ \\
& Bassier et al. (2019) & $\begin{array}{l}\text { Towards Semantic Interoperability } \\
\text { Standards based on Ontologies }\end{array}$ \\
& & $\begin{array}{l}\text { Creating Information Delivery } \\
\text { Specifications using Linked Data } \\
\text { The application of web of data } \\
\text { technologies in building materials }\end{array}$ \\
& Bauer et al. (2019) & \\
& Berlo et al. (2019) & \\
& Bilal et al. (2017) &
\end{tabular}


Semantic web for information exchange between the building and manufacturing industries: a literature review

\begin{tabular}{|c|c|c|}
\hline No & Authors & Title \\
\hline & & $\begin{array}{l}\text { information modelling for } \\
\text { construction waste analytics }\end{array}$ \\
\hline 6 & Bonduel et al. (2018) & $\begin{array}{l}\text { The IFC to linked building data } \\
\text { converter - Current status }\end{array}$ \\
\hline 7 & Corry et al. (2015) & $\begin{array}{l}\text { A performance assessment ontology } \\
\text { for the environmental and energy } \\
\text { management of buildings }\end{array}$ \\
\hline 8 & Costa et al. (2015) & $\begin{array}{l}\text { Connecting building component } \\
\text { catalogues with BIM models using } \\
\text { semantic technologies: An application } \\
\text { for precast concrete components }\end{array}$ \\
\hline 9 & Costa (2017) & $\begin{array}{l}\text { Integration of building product data } \\
\text { with BIM modelling: a semantic-based } \\
\text { product catalogue and rule checking } \\
\text { system }\end{array}$ \\
\hline 10 & Felic et al. (2014) & $\begin{array}{l}\text { Process-oriented semantic knowledge } \\
\text { management in Product Lifecycle } \\
\text { Management }\end{array}$ \\
\hline 11 & Gao et al. (2014) & $\begin{array}{l}\text { BIMTag: Semantic annotation of web } \\
\text { BIM product resources based on IFC } \\
\text { ontology }\end{array}$ \\
\hline 12 & Godager (2018) & $\begin{array}{l}\text { Critical review of the integration of } \\
\text { BIM to semantic web technology }\end{array}$ \\
\hline 13 & Gudnason and Pauwels (2016) & $\begin{array}{l}\text { SemCat: Publishing and accessing } \\
\text { building product information as linked } \\
\text { data }\end{array}$ \\
\hline 14 & Huang et al. (2019) & $\begin{array}{l}\text { Data-driven ontology generation and } \\
\text { evolution towards intelligent service } \\
\text { in manufacturing systems }\end{array}$ \\
\hline 15 & Krima et al. (2012) & $\begin{array}{l}\text { Dynamic customization and } \\
\text { validation of product data models } \\
\text { using semantic web tools }\end{array}$ \\
\hline 16 & Lou (2011) & $\begin{array}{l}\text { A method toward building semantic- } \\
\text { enriched product model }\end{array}$ \\
\hline 17 & Lu et al. (2015) & $\begin{array}{l}\text { Enriching the semantics of variational } \\
\text { geometric constraint data with } \\
\text { ontology }\end{array}$ \\
\hline 18 & Moreno et al. (2011) & $\begin{array}{l}\text { Application of Product Data } \\
\text { Technology Standards to LCA Data }\end{array}$ \\
\hline 19 & Niknam et al. (2019) & $\begin{array}{l}\text { Integrating BIM and product } \\
\text { manufacturer data using the Semantic } \\
\text { web technologies }\end{array}$ \\
\hline 20 & Niknam et al. (2017) & $\begin{array}{l}\text { A shared ontology approach to } \\
\text { semantic representation of BIM data }\end{array}$ \\
\hline 21 & Pauwels et al. (2017) & $\begin{array}{l}\text { Semantic web technologies in AEC } \\
\text { industry: A literature overview. } \\
\text { Automation in Construction }\end{array}$ \\
\hline 22 & Pauwels et al. (2016) & $\begin{array}{l}\text { EXPRESS to OWL for construction } \\
\text { industry: Towards a recommendable } \\
\text { and usable ifcOWL ontology }\end{array}$ \\
\hline 23 & Pauwels et al. (2015) & $\begin{array}{l}\text { Linked Data in Architecture and } \\
\text { Construction }\end{array}$ \\
\hline 24 & Scherer et al. (2011) & $\begin{array}{l}\text { A distributed multi-model-based } \\
\text { Management Information System for } \\
\text { simulation and decision-making on } \\
\text { construction projects }\end{array}$ \\
\hline 25 & Shayeganfar et al. (2013) & An ontology-aided optimization \\
\hline
\end{tabular}




\begin{tabular}{lll}
\hline No & Authors & Title \\
\hline & & approach to eco-efficient building \\
& design \\
26 & Wagner and Ruppel (2019) & BPO: The Building \\
& Product Ontology for Assembled \\
& Products \\
\hline
\end{tabular}

\section{RESULTS}

\subsection{Descriptive Analysis}

The identified papers are classified by year to see the distribution of them across the years. Figure 2 shows that $23.08 \%$ of the retrieved paper is published in the year 2019 taking the lead. The next higher number of papers are published in 2015 and 2017 each with percentage of $15.38 \%$. This figure displays the research community's growing interest in the analysed subject.

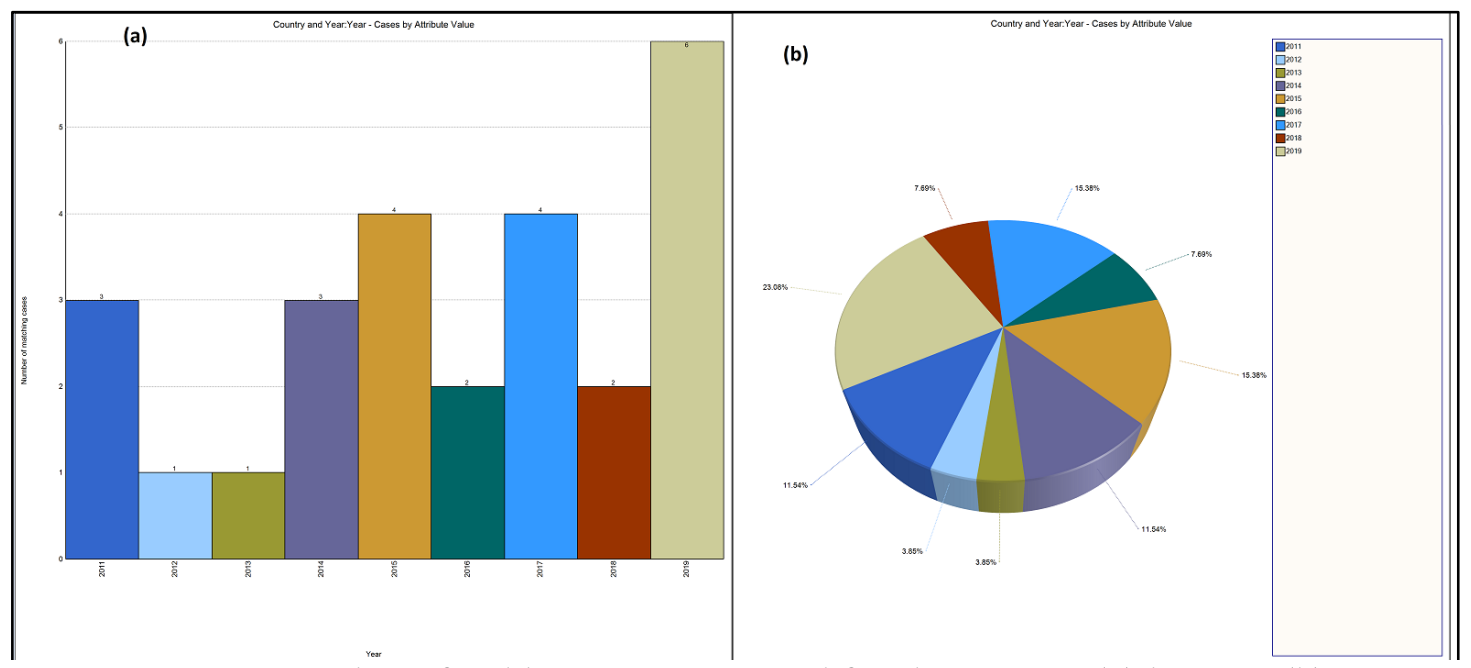

Figure 2 Number of Publications Retrieved for the Review (a) by year (b) in percentage

Booth et al. (2016) characterized three types of data synthesis in a systematic literature reviews namely aggregative, configurative and integrative. This research followed the aggregative data synthesis approach as the intention of the research was to bring multiple studies together and examine concepts or ideas that are relevant to answer the research question.

The identified papers are exported to NVivo 12 for data extraction and subsequent qualitative data analysis. The data extraction was guided by the review's research question while identifying and coding the relevant information in NVivo.

Booth et al. (2016) suggest to starting the qualitative analysis of the review by reading through the retrieved papers with subsequent selecting of an index paper. They defined index paper as a paper selected from the retrieved papers based on its conceptual richness, number of citations, age etc., for the purpose of comparing all papers against the chosen index paper. In addition, the selection of the index paper is influenced by the purpose of the review. Because of its conceptual richness and relative high number of citations, the paper Pauwels et al. (2017) was chosen as an index paper against which concepts extracted from other retrieved papers are compared with and categorized accordingly while reporting the findings of the review. Pauwels et al. (2017) conducted 
an extensive literature overview related to the development and application progress of semantic web technologies in the AEC domains. They have outlined three application areas of the semantic web as shown in Table 5, namely: interoperability, linking across domains and logical inference and proofs.

This review specifically emphasizes the area of product information exchange between the building and product manufacturers which Pauwels et al. (2017) categorizes this area under "linking across domains" application area. Based on the scope of the review, the first three use cases mentioned under the category "Linking across domains" (see Table 5) were chosen as a model or framework through which the benefits are extracted and categorized. The use cases are:

- ontology-based information management and sharing,

- combine product manufacturer data with building data and

- support building performance analysis and optimization.

It is worth mentioning that all application areas are not mutually exclusive.

\subsection{Result}

\subsubsection{Benefits of the Semantic Web and Linked Data Technologies}

Ontology-based information management and sharing: Ontologies serve as a medium to represent and model information using ontology languages such as the Resource Description Framework Schema (RDFS) and Web Ontology Language (OWL). These technologies offer an opportunity to model and combine heterogenous information from diverse knowledge domains (Pauwels et al., 2017). Gudnason and Pauwels (2016) mentioned how building product information are heterogeneous, unstructured and produced in incompatible semantics in the building industry. It is a current trend that manufacturers provide their product information mostly in PDF format (Niknam et al., 2019, Costa and Madrazo, 2015, Berlo et al., 2019). Consequently, building designers are obliged to manually insert this information into their BIM tools, which is usually errorprone and inefficient (Niknam et al., 2019). Hence, there is a need for an integration of product data using ontology where data is structured and connected on the web so that it can be processed by machines (Niknam and Karshenas, 2017).

Table 5 Use cases of semantic web technologies in the AEC industries (Pauwels et al., 2017)

\begin{tabular}{lll}
\hline Interoperability & Linking across domains & $\begin{array}{l}\text { Logical inference and } \\
\text { proofs }\end{array}$ \\
\hline $\begin{array}{l}\text { Enable vendor-neutral } \\
\text { model exchange }\end{array}$ & $\begin{array}{l}\text { Ontology-based } \\
\text { information management } \\
\text { and sharing }\end{array}$ & $\begin{array}{l}\text { Check model consistency } \\
\text { and completeness }\end{array}$ \\
$\begin{array}{l}\text { Combine different } \\
\text { information } \\
\text { representations }\end{array}$ & $\begin{array}{l}\text { Combine product } \\
\text { manufacturer data with } \\
\text { building data }\end{array}$ & $\begin{array}{l}\text { Enable automated } \\
\text { regulation compliance } \\
\text { checking }\end{array}$ \\
$\begin{array}{l}\text { Support use case-based } \\
\text { information exchange }\end{array}$ & $\begin{array}{l}\text { Support building } \\
\text { performance analysis and } \\
\text { optimization }\end{array}$ & $\begin{array}{l}\text { Logical inference use } \\
\text { cases including building } \\
\text { energy performance, } \\
\text { construction safety, cost } \\
\text { estimation, home } \\
\text { automation and etc. }\end{array}$ \\
& &
\end{tabular}


Connect BIM and GIS

Enable automated

regulation compliance

checking

Several studies suggested an ontology-based information management method to unify and integrate heterogeneous data from diverse data sources (Pauwels et al., 2017, Gudnason and Pauwels, 2016, Costa and Madrazo, 2015, Huang et al., 2019). In this regard, ontologies offer the possibility "to collect and combine data from multiple heterogeneous sources and provide a homogeneous view of information thereby making the information accessible and useable to the end users and applications" (Costa and Madrazo, 2015). Ontology-based product data management is also acknowledged and embraced in the technical roadmap of the buildingSMART as showed in Figure 3. The most popular three BIM adoption levels are extending to the next level to incorporate the application of semantic technologies in product data management on the basis of ontology (Pauwels et al., 2017, Godager, 2018). This calls for attention and preparation for all domains involved in the AEC industry, including the manufacturers.

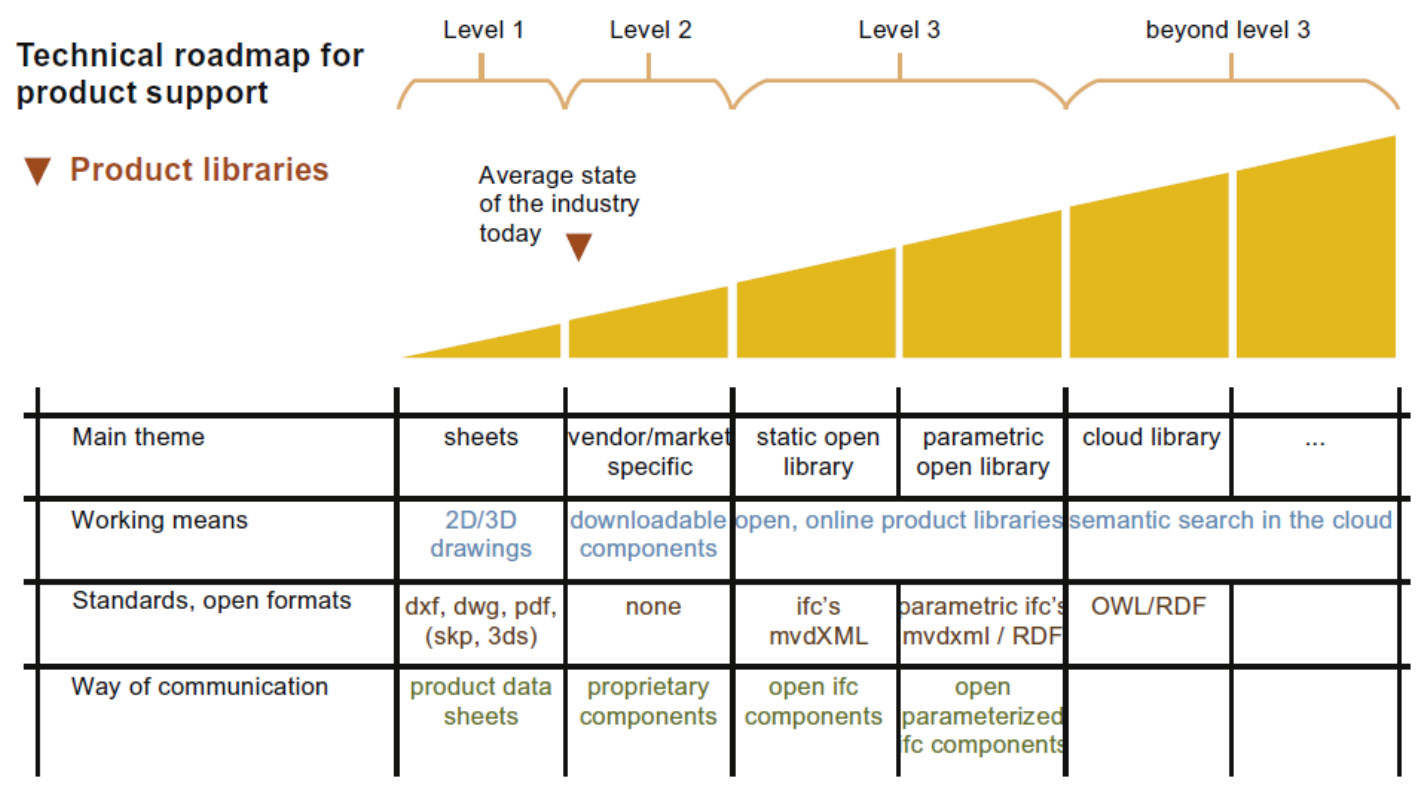

Figure 3 The technical roadmap for product support (Pauwels et al., 2017)

Numerous studies collected for this review adopted the definition of an ontology as a 'formal, explicit specification of a shared conceptualization', that provides a shared vocabulary that can be used to model semantic information effectivity (Niknam et al., 2019, Costa and Madrazo, 2015, Moreno et al., 2011, Lu et al., 2015, Costa Jutglar, 2017). Thus, ontologies have the potential to enrich the semantics of product geometry as well as express the semantics of product data unambiguously. With the use of ontology, it has become possible to easily describe the real-world products in a homogeneous machineprocessable format (Shayeganfar et al., 2013, Abdul-Ghafour et al., 2014, Bassier et al., 2019, Wagner and Rüppel, 2019). Modelling and representing knowledge in this manner 
Semantic web for information exchange between the building and manufacturing industries: a literature review

facilitates an automated searching and using of building product data at the early design stage thereby enabling designers to optimize their design decisions (Shayeganfar et al., 2013).

Furthermore, ontologies are useful to represent knowledge formally and create a shared knowledge base, from which knowledge can be inferred automatically which allows manufacturers develop an idea or concept for their new products (Felic et al., 2014). Once ontology is developed, an added benefit such as reasoning to infer logical conclusion, consistency checking and semantic queries can be performed. This enables data integration, creation of new knowledge from the existing data and execution of sophisticated data query in multiple domains (Pauwels et al., 2017, Godager, 2018, Lu et al., 2015, Krima et al., 2012).

Combine product manufacturer data with building data: One of the envisaged benefits by adopting the SW technologies in the building industry includes the ability to link building information models with the product manufacturer's data (Godager, 2018, Pauwels et al., 2015). Manufacturer's product descriptions required to conduct building performance analysis can be readily accessible, usable and searchable on the web with the unifying language of semantic web and linked data (Pauwels et al., 2017). Data stemming from both the building and manufacturing domain can be described and linked homogeneously in RDF, using the RDF triples subject-predicate-object (Corry et al., 2015). This opens an opportunity for designers to explore possible design alternatives to optimize building performances. On the other hand, it increases collaboration of the involved actors through a com-mon platform and encourages the engagement of building product manufacturers during the design stage (Pauwels et al., 2017, Costa and Madrazo, 2015, Shayeganfar et al., 2013).

Manufacturers have been using standard product data templates, such as Specifier's Properties information exchange (SPie), and catalogues of BIM objects, such as BIMobject, to deliver BIM data. Such templates model and exchange information based on open industry standards (Gudnason and Pauwels, 2016). Gudnason and Pauwels (2016) mentioned that the application of such templates has been improving and have added value within the construction supply chain. However, the marketing business models of the manufacturers supply chain has not been improved for several years (ibid). As a result, "information providers collect product information in web portals from manufacturers, usually for a fee, to allow designers to search, analyse, compare and reuse the information" (ibid). The application of the semantic web and linked data prove to be suitable to support the manufacturers' supply chain for representing the engineering properties of product design as well as managing product information by: "linking product data with other data sets, creating customized data sets for specific stakeholders and providing suppliers with detailed and structured product data"(ibid).

Currently, one of the major problems in the building performance optimization process include lack of mechanisms for comparing products of the same type sup-plied by different manufacturers (Moreno et al., 2011). To carry out a legitimate comparison of products, real and timely information about the product and processes as well as information about the precise inputs into those products and processes is required (Moreno et al., 2011, Shayeganfar et al., 2013). A good example would be comparison of products from the environmental point of view which can be achieved with LCA (Moreno et al., 2011). It is well known that LCA requires the gathering of real data throughout the life cycle of the product. Therefore, "it is necessary to know what resources have been consumed and what waste has been emitted to the environment in 
the making of each part within an assembly of the product" (ibid). In this regard, the semantic web enables product manufacturers to browse the supply chain and gather information about each component of the product. All products, product components, and activities can be represented as a resource in RDF and uniquely identified by uniform resource identifier (URI) (ibid). The URI can then be imprinted on the product to make the information about the product available whenever is needed (ibid). It should be mentioned that, while the URI always represents the same product in both human and computer readable for-mat, there is also a need to maintain the data on the web throughout the lifecycle of the product. This helps to facilitate maintenance as well as provides information on the final disposal of products (ibid).

Another benefit empowered by the semantic web technology is the ability to publish concept libraries in both top down and bottom up approach (Pauwels et al., 2017, Berlo et al., 2019). The top down approach necessitates the need for international product classification standard within large concept libraries. The bsDD is an example of top down approach which enables end users explicitly identify convenient products for their specific cases (Pauwels et al., 2017, Berlo et al., 2019). On the other hand, the bottom up approach offers end users the ability to create and manage new concept libraries in distributed manner as opposed to the centralized data management that relies on common data standards (Berlo et al., 2019, Godager, 2018). This would in turn make extensibility easier and provide designers the flexibility they need to realize various design scenarios instead of being limited to the predetermined design alternatives as it is with top down approach (Berlo et al., 2019, Niknam and Karshenas, 2017). As it is mentioned by Pauwels et al. (2017), a bottom up approach encourages to 'try to interpret, accommodate and model what is, rather than trying to change reality to fit a single model'.

Support building performance analysis and optimization: Shayeganfar et al. (2013) indicates the gap between real world product description and the way they are abstracted in BIM tools. This gap created discrepancy between the real performance of a building and the simulated performance of a building model (Corry et al., 2015). Shayeganfar et al. (2013) continues to explain the potential of the semantic web technologies to bridge this gap given the fulfilment of two prominent components. First, an ontology that describe the real product needs to be created. This includes developing ontologies for different domains required for performance simulations such as construction product standards and regulations, product specification including product cost information, climate data etc. Second, these product descriptions need to be linked with the building performance assessment and optimization environment to enable investigation of the available design alternatives.

\subsubsection{Limitations of the Semantic Web and Linked Data Technologies}

The primary challenge of the building industry has been the lack of standard BIM-related shared knowledge base (ontology). As a result, the semantic of terms and concepts are incompatible between different applications often resulting in misinterpretation of concepts and loss of information during information exchanges (Lou, 2011, Gao et al., 2014).

To address this challenge, several research efforts have been made to represent the BIM-IFC data with a semantic format by first converting the IFC schema into an OWL ontology known as ifcOWL as general-ontology (Godager, 2018, Scherer and Schapke, 2011, Pauwels and Terkaj, 2016, Bonduel et al., 2018). The ifcOWL is equivalent to the 
present large and complex IFC EXPRESS schema. Currently the ifcOWL has reached the point where the use of it is encouraged while there still remains issues to address particularly regarding whether or not to convert IFC geo-metric data that requires little semantic meaning (Pauwels et al., 2017). Furthermore, the developed ifcOWL, as equivalent to the IFC EXPRESS schema, is still large and complex which negatively affected the searchability of information (Bonduel et al., 2018).

Other research initiatives in this area include generating an ontology for a specific instance models as domain-ontology rather than directly converting the IFC format to OWL (Pauwels and Terkaj, 2016). This allows individual manufacturers develop their own ontology to capture their specific product data. This approach, however, makes the information isolated and difficult to find for reusing for others outside of the scope (Gudnason and Pauwels, 2016).

Furthermore, the creation and maintenance of links between different datasets has been reported as a challenge in the application of these technologies (Huang et al., 2019, Godager, 2018). The practical implication of this in building industry would be the challenge of maintaining the Linked Building Data (LBD) of products linked and combined with their environmental assessment as RDF statements. RDF statements describing products from real world are open to amendment whenever there is change. In such cases, the RDF triples can be inserted or eliminated to keep the repositories updated. This inevitably affect other links, could cause link breakage or links disappear with no notification (Regino et al., n.d.). It was also noted that ontologies are usually created manually by domain specific experts and ontology experts, which is time consuming and inefficient (Huang et al., 2019, Bauer et al., 2019). In both scenarios mentioned above, full automatic link maintenance and ontology generation has been a research problem in the application of the SW and LD technologies (Huang et al., 2019, Regino et al., n.d.).

The application of the semantic web also put demands on the manufacturers to create product data ontology for their products and make their product data available and transferrable as well as shared and reused (Niknam et al., 2019). This eventually imposes two challenges for the manufacturers. First, manufacturers are not motivated to share their detailed product information openly with the intention of maintaining their competitive market share and distinguishing their product characteristics among their rivals. Second, most building product manufacturers are medium and small size companies with limited economy and adopting the semantic web technology would mean significant investment in complying with industry product specification (Gudnason and Pauwels, 2016).

\subsubsection{Limitations of Existing BIM Technologies}

Currently, the EXPRESS-based IFC schema is widely used as an open exchange standard for representing building information in neutral format. IFC is able to successfully exchange information associated with product geometry (Abdul-Ghafour et al., 2014). However, several studies show how the explicit semantics of product data cannot be represented and automatically exchanged by existing standards (Godager, 2018, Moreno et al., 2011, Lu et al., 2015). There are possible ways to extend the IFC definitions, to include the semantics of products, using IfcProxyElement, Property sets and referring to elements in bsDD and external object type library (Berlo et al., 2019). However, the IFC schema requires strong familiarity with the EXPRESS language to take advantage of its extensibility and it has not been possible to extend the IFC schema on-the-fly in a userfriendly way (Pauwels et al., 2017, Bonduel et al., 2018). 
Bilal et al. (2017) and Gao et al. (2014) also added the data of building design can be captured by the IFC schema while the data of building products, such as cost, alternative products, product functions, dimensions, materials, performance, attainability, manufacturers etc., are not yet embedded in the product and are provided by the manufacturers as an associate document to BIM models. Besides, consistency checking, reasoning and semantic queries are difficult to apply on the IFC building models (Lu et al., 2015). In general, as it is explained by Godager (2018), the semantic web ontologybased approach significantly diminishes the major challenges of the current standards.

Thus, SW and LD benefits can be summarized as follows:

- Ontology-based information management and sharing can:

- enable the sharing of heterogeneous information;

- achieve a shared vocabulary;

- create a more stable development of repositories concepts dictionary and concept library;

- represent the real-world products in a homogeneous machine-processable format;

- facilitate an automated searching and using of building product data at the early design stage thereby enabling designers to optimize their design decisions;

- enable data integration, creation of new knowledge from the existing data and execution of sophisticated data query in multiple domains;

- LD and SW technology seem to support reasoning and search in a better manner than most other alternatives.

Through Combine product manufacturer data with building data, it is possible to:

- link building information models with the product manufacturer's data;

- access, use and search on the web manufacturer's product descriptions re-quired to conduct building performance analysis;

- homogeneously describe and link data stemming (from both the building and manufacturing domain) in RDF;

- support the manufacturers supply chain for representing the engineering properties of product design as well as managing product information;

- capture real and up-to-date information about the product using product ontology;

- publish concept libraries in both top down and bottom up approach.

- facilitate the bottom-up approach which would give the producers the opportunity to describe their products using different properties and let designers to search for products with other properties than the ordinary ones.

Support building performance analysis and optimization allows to

- bridge the gap between real world product description and how they are abstracted in BIM tools. 
Semantic web for information exchange between the building and manufacturing industries: a literature review

From the conducted literature study, SW and LD limitations can be summarized as:

- semantic of terms and concepts are incompatible between different applications often resulting in misinterpretation of concepts and loss of information during information exchanges;

- ontologies are usually created manually by domain specific experts and ontology experts indicating the need for automatically generating ontologies from databases;

- application of the semantic web put demands on the manufacturers to create product data ontology for their products and make their product data available and transferrable as well as shared and reused (Niknam et al., 2019).

\section{DISCUSSION AND CONCLUSION}

In this paper, a literature review was conducted to investigate whether the SW and LD technologies could be a better alternative to exchange information between the building and product manufacturing industries in comparison with the openBIM standards. This goal was achieved by studying the benefits and limitations of these technologies along with the limitations of the existing openBIM information ex-change technologies.

The result showed that the adoption of the SW and LD technologies facilitates an ontology-based information management and sharing. In view of this, ontology development languages provide an opportunity to define the basic terms and relations of domain of interest, as well as the rules for combining these terms and relations. This enables to formalize and represent almost all types of information on the web using a shared vocabulary thereby providing the basis for interoperability between systems. Furthermore, ontologies enable manufacturers to freely describe their products in a homogeneous machine-processable format while making them available for sharing and re-using. The added benefits of using ontologies include reuse, sharing, consistency checking, reasoning over ontology relations to facilitate inferring new conclusion, portability of knowledge across platforms, and improved documentation, semantic queries, maintenance, and reliability.

Upon the development of ontologies, they can be used as a basis for integration of information sources and as a query model for information sources. A significant application of integration of information sources, which is demonstrated by several studies, is the ability to combine product manufacturers' data with the building data. Data generated by these sources can be integrated and made available using the same data format and reachable using common API (Wood et al., 2014). In this regard, manufacturers will have the opportunity to capture real and up-to-date information about the engineering properties of their products and processes using the RDF data model. They can publish this information as a file or in a database, which in both cases, can be searchable via the SPARQL query language and usable by the building industry who have access to the data (Wood et al., 2014). SW and LD technologies can also be used to address the gap between the real-world product description and their abstraction in BIM tools through developing ontologies for different domains required for performance simulations such as construction product standards and regulations, product specification including product cost information, climate data etc. This 
eventually provides building designers the required information necessary for their design simulation and optimization process.

However, the promising potential of the SW and LD can be fully utilized by the industry when all processes involved in the building lifecycle are operating based on ontology-based information management approach by putting into effect both the top down and bottom up approach of formalizing, standardizing and re-using of concepts and properties. The practical implementation, however, needs to be progressively incremental.

Studies suggest the application of semantic web as supplemental to the existing technologies for rational reasons. One reason is that IFC is already widely used in the industry and supported by large number of BIM software applications. The other reason is numerous actors including engineers, designers, manufacturers etc. use different software applications and have their own way of representing their knowledge. Changing the way these actors work could be an added overload to all parties.

This literature study showed that, even though several research initiatives have put efforts in the application of SW and LD technologies in the building industry, the implementation of these technologies is still open for further research and discussions. Future research, in connection with MAP4Light, will extend this work by creating an ontology for lighting product data and integrating the data in BIM tool for conducting lighting simulations.

\section{REFERENCES}

Abdul-Ghafour, S., Ghodous, P., Shariat, B., Perna, E. and Khosrowshahi, F. (2014). Semantic interoperability of knowledge in feature-based CAD models. ComputerAided Design, 56, pp.45-57.

Bassier, M., Bonduel, M., Derdaele, J. and Vergauwen, M. (2019). Towards the Semantic Enrichment of Existing Online 3D Building Geometry to Publish Linked Building Data. In Iberoamerican Knowledge Graphs and Semantic Web Conference (pp. 134148). Springer, Cham.

Bauer, M., Baqa, H., Bilbao, S., Corchero, A., Daniele, L., Esnaola, I., Fernández, I., Frånberg, Ö., Castro, R.G., Girod-Genet, M. and Guillemin, P. (2019). Towards semantic interoperability standards based on ontologies.

van Berlo, L., Willems, P. and Pauwels, P. (2019). Creating Information Delivery Specifications using Linked Data. In 36th CIB W78 2019 Conference (pp. 647-660).

Bilal, M., Oyedele, L.O., Munir, K., Ajayi, S.O., Akinade, O.O., Owolabi, H.A. and Alaka, H.A. (2017). The application of web of data technologies in building materials information modelling for construction waste analytics. Sustainable materials and technologies, 11, pp.28-37.

Bonduel, M., Oraskari, J., Pauwels, P., Vergauwen, M. and Klein, R. (2018). The IFC to linked building data converter: current status. In 6th Linked Data in Architecture and Construction Workshop (Vol. 2159, pp. 34-43).

Booth, A., Sutton, A. and Papaioannou, D. (2016). Systematic approaches to a successful literature review. Sage.

Burnham, J.F. (2006). Scopus database: a review. Biomedical digital libraries, 3(1), p.1.

Cavka, H.B., Staub-French, S. and Poirier, E.A., 2017. Developing owner information requirements for BIM-enabled project delivery and asset management. Automation in construction, 83, pp.169-183. 
Corry, E., Pauwels, P., Hu, S., Keane, M. and O'Donnell, J. (2015). A performance assessment ontology for the environmental and energy management of buildings. Automation in Construction, 57, pp.249-259.

Costa, G. and Madrazo, L. (2015). Connecting building component catalogues with BIM models using semantic technologies: an application for precast concrete components. Automation in construction, 57, pp.239-248.

Costa Jutglar, G. (2017). Integration of building product data with BIM modelling: a semantic-based product catalogue and rule checking system (Doctoral dissertation, Universitat Ramon Llull).

Eastman, C.M., Eastman, C., Teicholz, P., Sacks, R. and Liston, K. (2011). BIM handbook: A guide to building information modeling for owners, managers, designers, engineers and contractors. John Wiley \& Sons.

Felic, A., König-Ries, B., \& Klein, M. (2014). Process-oriented semantic knowledge management in product lifecycle management. Procedia Cirp, 25(0), 361-368.

Gao, G., Liu, Y. S., Wang, M., \& Han, X. G. (2014). BIMTag: semantic annotation of web BIM product resources based on IFC ontology. In The 21st International workshop: intelligent computing in engineering.

Godager, B. A. (2018). Critical review of the integration of BIM to semantic web technology.

Gudnason, G., \& Pauwels, P. (2016). SemCat: publishing and accessing building product information as linked data. In Proceedings of 11th European Conference on product \& process modelling (ECPPM) (pp. 659-666).

Huang, C., Cai, H., Xu, L., Xu, B., Gu, Y., \& Jiang, L. (2019). Data-driven ontology generation and evolution towards intelligent service in manufacturing systems. Future Generation Computer Systems, 101, 197-207.

Jalilzadehazhari, E., Johansson, P., Johansson, J., \& Mahapatra, K. (2017). Application of analytical hierarchy process for selecting an interior window blind. Architectural Engineering and Design Management, 13(4), 308-324.

Jalilzadehazhari, E., Pardalis, G., Johansson, J., \& Johansson, P. (2019). Application of multi-objective optimization for resolving conflicts when selecting windows. In The 9th International Conference on Sustainable Development in the Building and Environment (SuDBE2019) \& the International Forum of Green and Healthy Buildings. Reading and Cambridge, UK. 22nd to 28th July 2019.

Jalilzadehazhari, E., Vadiee, A., \& Johansson, P. (2019). Achieving a Trade-Off Construction Solution Using BIM, an Optimization Algorithm, and a Multi-Criteria Decision-Making Method. Buildings, 9(4), 81.

Krima, S., Feeney, A. B., \& Foufou, S. (2012, July). Dynamic customization and validation of product data models using semantic web tools. In IFIP International Conference on Product Lifecycle Management (pp. 569-577). Springer, Berlin, Heidelberg.

Adriaanse, L. S., \& Rensleigh, C. (2013). Web of science, scopus and Google Scholar. The Electronic Library.

Lou, Y. (2011, September). A method toward building semantic-enriched product model. In 2011 International Conference on Electronics, Communications and Control (ICECC) (pp. 1826-1830). IEEE.

Lu, W., Qin, Y., Liu, X., Huang, M., Zhou, L., \& Jiang, X. (2015). Enriching the semantics of variational geometric constraint data with ontology. Computer-Aided Design, 63, 72-85.

Mongeon, P., \& Paul-Hus, A. (2016). The journal coverage of Web of Science and Scopus: a comparative analysis. Scientometrics, 106(1), 213-228. 
Moreno, A., Cappellaro, F., Masoni, P., \& Amato, A. (2011). Application of product data technology standards to LCA data. Journal of Industrial Ecology, 15(4), 483-495.

Negendahl, K. (2015). Building performance simulation in the early design stage: An introduction to integrated dynamic models. Automation in Construction, 54, 39-53.

Niknam, M., Jalaei, F., \& Karshenas, S. (2019). Integrating BIM and product manufacturer data using the semantic web technologies. Journal of Information Technology in Construction (ITcon), 24(22), 424-439.

Niknam, M., \& Karshenas, S. (2017). A shared ontology approach to semantic representation of BIM data. Automation in Construction, 80, 22-36.

Pauwels, P., Zhang, S., \& Lee, Y. C. (2017). Semantic web technologies in AEC industry: A literature overview. Automation in Construction, 73, 145-165.

Pauwels, P., \& Terkaj, W. (2016). EXPRESS to OWL for construction industry: Towards a recommendable and usable ifcOWL ontology. Automation in Construction, 63, 100133.

Pauwels, P., Törmä, S., Beetz, J., Weise, M., \& Liebich, T. (2015). Linked data in architecture and construction. Automation in construction, 57(2015), 175-177.

Regino, A. G., Matsoui, J. K. R., dos Reis, J. C., Bonacin, R., Morshed, A., \& Sellis, T. Link maintenance for integrity in linked open data evolution: Literature survey and open challenges.

Scherer, R. J., \& Schapke, S. E. (2011). A distributed multi-model-based management information system for simulation and decision-making on construction projects. Advanced Engineering Informatics, 25(4), 582-599.

Shayeganfar, F., Anjomshoaa, A., Heurix, J., Sustr, C., Ghiassi, N., Pont, U., ... \& Mahdavi, A. (2013). An ontology-aided optimization approach to eco-efficient building design. In Proceedings of the 13th Conference of International Building Performance Simulation Association (pp. 2194-2200).

UKBIM (2018). A fresh way forward for product data.

Wagner, A., \& Rüppel, U. (2019). BPO: The Building Product Ontology for Assembled Products. In Proceedings of the 7th Linked Data in Architecture and Construction workshop (LDAC 2019)', Lisbon, Portugal (p. 12).

Wood, D., Zaidman, M., \& Ruth, L. (2014). Structured data on the Web.

Zhang, C., Beetz, J., \& Weise, M. (2015). Interoperable validation for IFC building models using open standards. Journal of Information Technology in Construction (ITcon), 20(2), 24-39. 